\section{(2) OPEN ACCESS}

\title{
Clues to primary vismodegib resistance lie in histology and genetics
}

\author{
Qisi Sun, ${ }^{1}$ Lihi Atzmony, ${ }^{1,2,3}$ Theodore Zaki, $^{1}$ Albert Peng, ${ }^{4}$ Jeffrey Sugarman, ${ }^{5,6}$ \\ Keith A. Choate
}

'Department of Dermatology, Yale University School of Medicine, New Haven,

Connecticut, USA

${ }^{2}$ Department of Genetics, Yale University School of Medicine, New Haven, Connecticut, USA ${ }^{3}$ Sackler Faculty of Medicine, Tel Aviv University, Tel Aviv, Israel ${ }^{4}$ Redwood Family Dermatology, Santa Rosa, California, USA ${ }^{5}$ Department of Family Medicine, University of California San Francisco School of Medicine, San Francisco, California, USA ${ }^{6}$ Department of Dermatology, University of California San Francisco School of Medicine, San Francisco, California, USA ${ }^{7}$ Department of Pathology, Yale University School of Medicine, New Haven, CT, United States

\section{Correspondence to}

Dr Keith A. Choate, Department of Dermatology, Yale School of Medicine, New Haven, CT 06510,USA; Keith.Choate@ yale.edu

Received 16 January 2020 Revised 17 February 2020 Accepted 8 March 2020 Published Online First 26 March 2020

\section{Check for updates}

(C) Author(s) (or their employer(s)) 2020. Re-use permitted under CC BY-NC. No commercial re-use. See rights and permissions. Published by BMJ.

To cite: Sun Q, Atzmony L, Zaki T, et al. J Clin Pathol 2020;73:678-680.

\section{ABSTRACT}

Basal cell carcinoma (BCC) is the most common human malignant neoplasm. However, there are multiple BCC subtypes that share clinical features while demanding different management. We present a case of a woman with hundreds of BCCs throughout her body that were resistant to vismodegib and without other features of basal cell nevus syndrome. Histological results of biopsies taken from various sites revealed three lesions characteristic of infundibulocystic BCCs (IBCCS) and two BCCs. Paired whole-exome sequencing performed using DNA isolated from blood and one of her IBCCS uncovered a germline heterozygous SUFU (Suppressor of Fused) mutation. The downstream location of SUFU in the hedgehog pathway explains why its mutation results in IBCCs that will not respond to any therapeutics that target upstream components of SUFU. These results capture the significance of histological and genetic analysis in directing treatment.

\section{INTRODUCTION}

Basal cell carcinomas (BCCs) arise from aberrant activation of the hedgehog $(\mathrm{Hh})$ signaling pathway, a highly conserved evolutionary pathway crucial for the differentiation of embryonic structures such as the central nervous, integumentary and musculoskeletal systems. ${ }^{12}$ Within this pathway, $\mathrm{Hh}$ ligands bind to tumour suppressor PTCH1, relieving PTCH1's inhibitory effect on the protein, smoothened $(\mathrm{SMO}){ }^{3}$ Active SMO promotes the dissociation of glioma-associated oncogene homologues (GLIs) from SUFU (Suppressor of Fused), a tumour suppressor and negative regulator of the Hh pathway. This results in the activation of GLI transcription factors and initiates cell growth. ${ }^{4}$ Upregulation of this pathway, primarily via lossof-function mutations in PTCH1, is responsible for BCCs and nevoid basal cell carcinoma syndrome (Gorlin syndrome), a disorder characterised by multiple BCCs, skeletal abnormalities and predisposition to numerous tumours. ${ }^{56}$

Until recently, treatment mostly consisted of surgical modalities such as Mohs micrographic surgery (MMS). ${ }^{7}$ In 2012 and 2015, the US Food and Drug Administration (FDA) approved vismodegib and sonidegib, respectively, for treating locally advanced or metastatic BCCs. ${ }^{89}$ Both bind to and inhibit SMO, interfering with the Hh pathway and attenuating tumour growth. ${ }^{10}$ Here, we discuss a patient who presented with what appeared to be multiple BCCs resistant to vismodegib. Our findings illustrate the importance of using histology and genetic analysis to guide management.

\section{CASE PRESENTATION}

A woman in her 70s with a history of hundreds of rough and raised papules was referred for genetic investigation. She first noticed the pearly-pink and skin-coloured lesions when she was 38. Often accompanied by soreness and flaking before disappearing then reappearing, the papules occurred throughout her body, including torso and vulva, but most commonly appeared on the scalp, neck, face, back and hands. Her medical history is unremarkable. She had never been exposed to radiation or ingested arsenic. Family history is significant for a first cousin on her mother's side with a similar presentation of multiple papules and two sons with congenital ocular motor apraxia, a characteristic shared with syndromes caused by an impaired $\mathrm{Hh}$ pathway, such as Joubert syndrome. ${ }^{11}$ The phenotype has also been observed in four children from two unrelated families with the SUFU mutation. ${ }^{1}$ Despite an absence of extracutaneous features and an atypical lesion distribution, she was originally diagnosed with trichoepitheliomas (TEs).

On examination, she had no palmar or plantar pits, jaw keratocysts, facial dysmorphology, developmental delay or other features suggestive of Gorlin syndrome.

Histopathological examination of individual pearly papules and plaques revealed either superficial BCCs or infundibulocystic BCCs (IBCCs) (figure 1). During this time, she had been treated with photodynamic therapy, MMS and 5 -fluorouracil cream.

In early 2018, she initiated therapy with $150 \mathrm{mg}$ of vismodegib daily. After a year of treatment, the size and number of her tumours had still not decreased. Instead, she experienced side effects of alopecia, muscle cramps and dysgeusia, which led to a $32 \mathrm{~kg}$ weight loss.

Faced with drug resistance and an increasing tumour burden, the patient gave written informed consent for genetic analysis at Yale University.

\section{METHODS AND RESULTS}

Paired whole-exome sequencing was performed using genomic DNA isolated from blood and biopsy of one of her IBCCs. No somatic mutations were identified. Plotting B-allele frequency across the genome demonstrated a segment of loss of heterozygosity (LOH) on chromosome 10 extending from position 53.4 Mbs to $135.4 \mathrm{Mbs}$. Copy number 


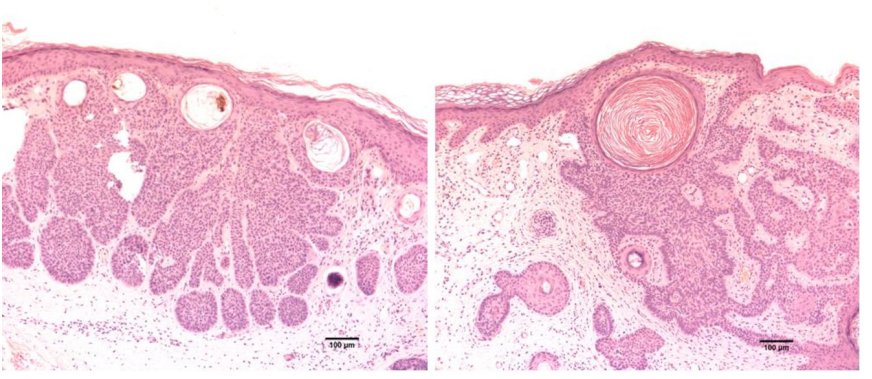

Figure 1 Histological features of infundibulocystic basalcell carcinomas (IBCCS). IBCCs with characteristic horn cysts within basaloid neoplasms composed of buds and cords with connections to the overlying epidermis ( $\mathrm{H} \& \mathrm{E}$, magnification $\times 10$ ).

analysis of whole-exome sequencing data suggested a copyneutral LOH. Analysis of germline variants within the LOH region revealed a heterozygous c.1093C $>$ T, p.Q365X mutation in the SUFU (OMIM 607035) gene (table 1). Sanger sequencing confirmed the heterozygosity of SUFU mutation in blood as well as its enrichment in the tumour (figure 2).

We took biopsies of different tumours from the patient's neck, scalp, forehead, arm and chest. Three lesions were characteristic of IBCCs; the other two were consistent with BCCs (figure 1).

\section{DISCUSSION AND CONCLUSION}

This case illustrates the importance of investigating the histological subtype of a patient's BCCs and performing genetic analysis before initiating vismodegib therapy. Through histological evaluation and discovery of a germline SUFU mutation, we conclude that the patient has multiple hereditary infundibulocystic basal cell carcinoma syndrome (MHIBCC), a rare yet distinct clinicopathological variant of BCC lacking the typical features of Gorlin syndrome. ${ }^{12}$ To our knowledge, there is only one other reported case of MHIBCC with vismodegib resistance. ${ }^{13}$ In addition to histological similarities, the prior case also shares many clinical features with ours, including onset in adulthood and numerous papules on face and vulva. ${ }^{12}$ Clinical features alone are not sufficient to guide treatment because there is often clinical overlap among the different BCC subtypes. For instance, our patient was originally diagnosed with TEs, which are clinically challenging to distinguish from IBCCs. According to established criteria for differentiating between the two, TEs have abundant fibrous stroma but the stroma in our patient's biopsy had few fibrocytes present. ${ }^{14}$ Distinguishing among the different subtypes of BCCs is crucial in guiding treatment decisions as each subtype has a different prognosis. ${ }^{15}$

Genetic analysis is also fundamental to determining proper management. Our investigation uncovered a germline SUFU mutation, a crucial piece of information that would have eliminated vismodegib as one of her treatment options. Vismodegib is ineffective in $S U F U$-associated IBCCs because $S U F U$ is
A

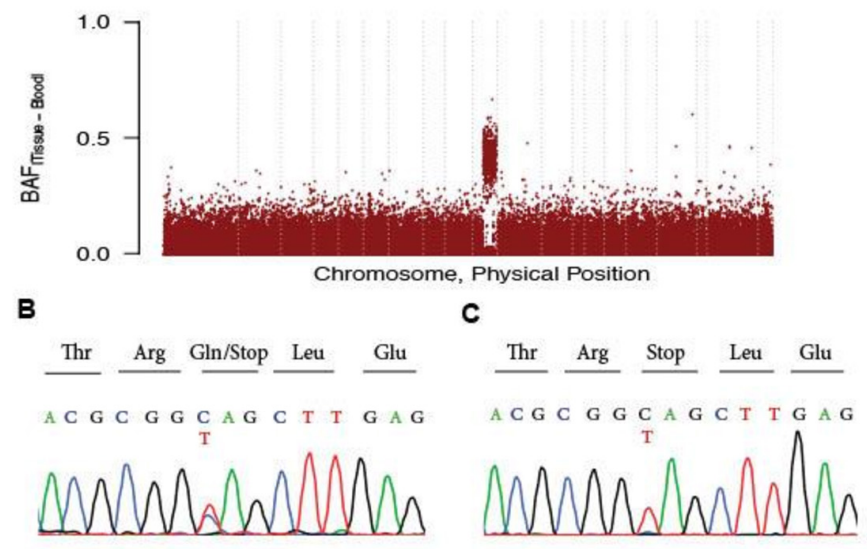

Figure 2 Germline heterozygous SUFU (Suppressor of Fused) mutation underlies non-syndromic multiple infundibulocystic basal cell carcinomas. Plot of B-allele frequency differences between affected tissue and saliva demonstrates somatic loss of heterozygosity on chromosome $10 \mathrm{q}$ that extends from $53.45 \mathrm{Mbs}$ to $135.37 \mathrm{Mbs}$ and contains the SUFU gene. (A) Dashed vertical lines separate individual chromosomes. (B) Sanger sequencing traces show heterozygous germline c.1093 C>T, p.Q365X mutation in SUFU. (C) This mutation is enriched in the affected tissue.

downstream of the drug's target, SMO, in the Hh pathway. A loss-of-function SUFU mutation disrupts the normal inhibitory effect of SUFU protein on GLI transcription factors, resulting in overactivation of target genes. ${ }^{16}$ Genetic testing before starting treatment would have saved the patient from the unnecessary side effects of $32 \mathrm{~kg}$ weight loss, loss of taste, cramps and alopecia.

The main treatment option for our patient now is MMS every few months. Since this presents a formidable cosmetic, physical and financial burden, it is worth considering other treatment modalities. GLI inhibitors like GLI antagonists and arsenic trioxide (ATO) have been developed as alternative options. ${ }^{17}$ In addition, although commonly used for its antifungal properties, itraconazole is a possible therapeutic option for BCCs given that a small trial revealed anti-BCC activity in humans. ${ }^{18}$ This finding may be explained by the fact that itraconazole is a potent $\mathrm{Hh}$ pathway inhibitor regardless of PTCH1 or SUFU mutation status. ${ }^{219}$ ATO combined with itraconazole may also be a therapeutic consideration since three out of five patients who tried the combination therapy in a small study experienced stable disease despite multiple adverse events. ${ }^{20}$ Indeed, further research and trials are needed on these alternative therapies.

We present our case to heighten awareness that although the subtypes of BCCs are difficult to distinguish clinically, not all should be treated equally. If a patient displays primary resistance to drug therapy, the clues to the mechanism can be revealed

Table 1 Exome sequencing statistics

\begin{tabular}{|c|c|c|c|c|c|c|}
\hline \multirow[b]{2}{*}{ Sample } & \multirow[b]{2}{*}{ Germline mutation } & \multicolumn{2}{|c|}{ No of reads in blood } & \multicolumn{2}{|c|}{ No of reads in infundibulocystic BCC } & \multirow[b]{2}{*}{ Somatic mutation } \\
\hline & & Ref. & Non-ref. & Ref. & Non-ref. & \\
\hline MOS100 & SUFU c. $1093 \mathrm{C}>\mathrm{T}, \mathrm{p} . \mathrm{Q}$ 365X & 38 & 47 & 14 & 110 & CN-LOH Chr10:53.4 Mb-135.4Mb* \\
\hline
\end{tabular}

*SUFU spans Chr 10:102 503 987-102633 535.

BCC, basal cell carcinoma; CN-LOH, copy-neutral loss of heterozygosity; non-ref, non-reference reads; ref, reference reads; SUFU, Suppressor of Fused. 
through histopathological investigation and genetic analysis, which can then more effectively guide therapy.

\section{Handling editor Runjan Chetty.}

Acknowledgements The authors thank the patient herself for providing a detailed history of her clinical course and contributing genetic samples to this work.

Funding This work is supported by the Yale School of Medicine Fellowship for Medical Student Research.

Competing interests None declared.

Patient consent for publication Not required.

Provenance and peer review Not commissioned; externally peer reviewed.

Open access This is an open access article distributed in accordance with the Creative Commons Attribution Non Commercial (CC BY-NC 4.0) license, which permits others to distribute, remix, adapt, build upon this work non-commercially, and license their derivative works on different terms, provided the original work is properly cited, appropriate credit is given, any changes made indicated, and the use is non-commercial. See: http://creativecommons.org/licenses/by-nc/4.0/.

ORCID iD

Keith A. Choate http://orcid.org/0000-0002-5857-7772

\section{REFERENCES}

1 De Mori R, Romani M, D'Arrigo S, et al. Hypomorphic recessive variants in Sufu impair the sonic hedgehog pathway and cause Joubert syndrome with cranio-facial and skeletal defects. Am J Hum Genet 2017;101:552-63.

2 Ogden T, Higgins S, Elbaum D, et al. The relevance of a suppressor of fused (Sufu) mutation in the diagnosis and treatment of Gorlin syndrome. JAAD Case Rep 2018:4:196-9.

3 Huang D, Wang Y, Tang J, et al. Molecular mechanisms of suppressor of fused in regulating the hedgehog signalling pathway. Oncol Lett 2018;15:6077-86.

4 Athar M, Li C, Kim AL, et al. Sonic hedgehog signaling in basal cell nevus syndrome. Cancer Res 2014;74:4967-75.
5 Pellegrini C, Maturo MG, Di Nardo L, et al. Understanding the molecular genetics of basal cell carcinoma. Int J Mol Sci 2017:18:2485.

6 Thalakoti S, Geller T. Chapter 8 - Basal cell nevus syndrome or Gorlin syndrome. In: Islam MP, Roach ES, eds. Handbook of clinical neurology. Elsevier, 2015: 119-28.

7 Lanoue J, Goldenberg G. Basal cell carcinoma: a comprehensive review of existing and emerging nonsurgical therapies. J Clin Aesthet Dermatol 2016;9:26-36.

$8 \operatorname{Sinx} \mathrm{KAE}$, Roemen GMJM, van Zutven V, et al. Vismodegib-Resistant basal cell carcinomas in basal cell nevus syndrome: clinical approach and genetic analysis. JAAD Case Rep 2018;4:408-11

9 Casey D, Demko S, Shord S, et al. FDA approval summary: sonidegib for locally advanced basal cell carcinoma. Clin Cancer Res 2017:23:2377-81.

10 Fellner C. Vismodegib (erivedge) for advanced basal cell carcinoma. PT 2012;37:670-82.

11 Wang SF, Kowal TJ, Ning K, et al. Review of ocular manifestations of Joubert syndrome. Genes 2018:9:605.

12 Schulman JM, Oh DH, Sanborn JZ, et al. Multiple Hereditary Infundibulocystic Basal Cell Carcinoma Syndrome Associated With a Germline SUFU Mutation. JAMA Dermatol 2016;152:323-7.

13 Schulman JM, Oh DH, Sanborn JZ, et al. Multiple hereditary Infundibulocystic basal cell carcinoma syndrome associated with a germline Sufu mutation. JAMA Dermatol 2016;152:323-7.

14 Crawford KM, Kobayashi T. Nevoid basal cell carcinoma syndrome or multiple hereditary infundibulocystic basal cell carcinoma syndrome? J Am Acad Dermatol 2004:51:989-95

15 Koelblinger P, Lang R. New developments in the treatment of basal cell carcinoma: update on current and emerging treatment options with a focus on vismodegib. Onco Targets Ther 2018;11:8327-40.

16 McMillan R, Matsui W. Molecular pathways: the hedgehog signaling pathway in cancer. Clin Cancer Res 2012;18:4883-8.

17 Rimkus TK, Carpenter RL, Qasem S, et al. Targeting the sonic hedgehog signaling pathway: review of smoothened and Gli inhibitors. Cancers 2016;8:22.

18 Kim DJ, Kim J, Spaunhurst K, et al. Open-Label, exploratory phase II trial of oral itraconazole for the treatment of basal cell carcinoma. J Clin Oncol 2014;32:745-51.

19 Kim J, Tang JY, Gong R, et al. Itraconazole, a commonly used antifungal that inhibits hedgehog pathway activity and cancer growth. Cancer Cell 2010;17:388-99.

20 Ally MS, Ransohoff K, Sarin K, et al. Effects of combined treatment with arsenic trioxide and itraconazole in patients with refractory metastatic basal cell carcinoma. JAMA Dermatol 2016;152:452-6. 